\title{
Prognostic Value of Pretreatment Serum Cystatin C Level in Nasopharyngeal Carcinoma Patients in the Intensity-modulated Radiotherapy Era
}

This article was published in the following Dove Press journal: OncoTargets and Therapy

\author{
Xi-Rong Tan* \\ Sheng-Yan Huang* \\ Sha Gong \\ Yang Chen \\ Xiao-Jing Yang \\ Qing-Mei He \\ Shi-Wei He \\ $\mathrm{Na}$ Liu (D) \\ Ying-Qing Li $\mathbb{C}$
}

State Key Laboratory of Oncology in South China; Collaborative Innovation Center of Cancer Medicine; Guangdong Key Laboratory of Nasopharyngeal Carcinoma Diagnosis and Therapy, Sun Yat-sen University Cancer Center, Guangzhou 510060, People's Republic of China

*These authors contributed equally to this work

\begin{abstract}
Purpose: Serum cystatin $\mathrm{C}$ has been considered as a significant prognostic factor for various malignancies. This study aimed to evaluate the relationship between serum cystatin $\mathrm{C}$ level before antitumor treatment and the prognosis of nasopharyngeal carcinoma (NPC) patients treated with intensity-modulated radiotherapy (IMRT).

Patients and Methods: A cohort of 2077 NPC patients were enrolled between April 2009 and September 2012. The Kaplan-Meier curves and log rank tests were used to determine the differences of overall survival (OS) and disease-free survival (DFS). Univariate and multivariate Cox regression analyses were used to determine independent prognostic factors. Results: Overall, 362/2077 (17.4\%) patients had high serum cystatin C level, and they were older and more male (both $P<0.001$ ), and they had higher TNM stage (all $P<0.05$ ). KaplanMeier analysis revealed that patients with high serum cystatin $\mathrm{C}$ had worse OS $(P<0.001)$ and DFS $(P<0.001)$. Univariate and multivariate Cox regression analysis showed that high serum cystatin $\mathrm{C}$ level was an independent prognostic predictor of OS (HR: $1.56,95 \% \mathrm{CI}$ : 1.25-1.95) and DFS (HR: 1.38, 95\%CI: 1.13-1.68). Subgroup analysis based on TNM stage revealed that advanced-stage NPC patients with high serum cystatin $\mathrm{C}$ had poorer OS $(P<0.001)$ and DFS $(P<0.001)$.
\end{abstract}

Conclusion: Our results revealed that high serum cystatin $\mathrm{C}$ level before antitumor treatment can predict clinical outcomes of NPC patients treated with IMRT, and it can guide clinicians to formulate more personalized therapy for NPC patients.

Keywords: nasopharyngeal carcinoma, serum cystatin C level, survival prognosis, predictor

\section{Introduction}

Nasopharyngeal carcinoma (NPC) is a kind of head and neck squamous cell carcinoma and has a unique distribution, with the highest incidence in southeast Asia, especially in southern China. ${ }^{1}$ Mainly originating from pharyngeal recess, an anatomical position close to skull base, NPC is sensitive to radiotherapy, alone or with chemotherapy. ${ }^{2}$ With the advent of diagnostic methods and treatment strategies, survival rate has been obviously increased in locally advanced NPC patients recently, ${ }^{3}$ but the number of patients dead from NPC keeps increasing across the whole world according to global cancer statistical data in 2018. ${ }^{4}$ Distant metastasis has become the major obstacle of treatment failure in NPC patients. ${ }^{5}$

The TNM staging system, comprised of the T, N, M classification, is the most significant tool for prognostic judgment and the key measure of treatment strategies. ${ }^{6}$ However, the TNM staging system is inadequate for predicting
Correspondence: Ying-Qing Li; Na Liu State Key Laboratory of Oncology in South China; Collaborative Innovation Center of Cancer Medicine; Guangdon Key Laboratory of Nasopharyngeal Carcinoma Diagnosis and Therapy, Sun Yat-sen University Cancer Center, 65I Dongfeng Road East, Guangzhou 510060, People's Republic of China Tel/Fax +86-20-87343255; +86-2087342370

Email liyingq।@sysucc.org.cn; liun I@sysucc.org.cn
OncoTargets and Therapy 2021:14 29-37

mit your manuscrip

DovePress $\boldsymbol{f}$ in $\boldsymbol{\nabla}$

http://doi.org/10.2147/0TTS286009 
prognosis of NPC patients for depending largely on the anatomy and ignoring biological heterogeneity of the tumor. ${ }^{7,8}$ Thus, it is still urgent to discover new biomarkers to predict the clinical outcome and the risk of distant metastasis of NPC patients. With the great development in the understanding of the molecular biology of NPC, numerous studies have found biomarkers for the prognosis or curative effect of NPC patients, such as albumin to globulin ratio, ${ }^{9}$ lactate dehydrogenase, ${ }^{10}$ C-reactive protein/albumin ratio, ${ }^{11}$ serum bilirubin, ${ }^{12}$ circulating lipoprotein, ${ }^{13}$ and plasma EBV-DNA level. ${ }^{14}$ Nevertheless, their clinical roles need to be confirmed and we are eager to find new and effective biomarkers to predict prognosis and guide treatment accurately.

Cystatin C, a 13-kD nonglycosylated protein and a cysteine protease inhibitor, is encoded by a housekeeping gene in almost all nucleated cells. ${ }^{15}$ Cystatin $\mathrm{C}$ affects protein catabolism, antigen presentation, bone resorption, and hormone processing, and it can couple to cleavage of membrane and extracellular matrix proteins during tissue remodeling irregularly, and its homeostasis imbalance can lead to disease, including cancer. ${ }^{16}$ Previous studies have shown that serum cystatin $\mathrm{C}$ level plays important roles in diagnosing and predicting human diseases, such as cirrhosis, ${ }^{17}$ inflammation, ${ }^{18}$ Parkinson's disease, ${ }^{19}$ kidney disease, ${ }^{20}$ and cardiovascular disease. ${ }^{21}$ Many studies have reported that cystatin $\mathrm{C}$ plays important roles in predicting the prognosis and effect of clinical therapy of various cancers, such as myeloma, ${ }^{22,}$ esophageal cancer, ${ }^{23}$ renal carcinoma, ${ }^{24}$ upper tract urothelial carcinoma, ${ }^{25}$ nonHodgkin's B-cell lymphoma, ${ }^{26}$ and so on. One study has described the potential relationship between cystatin $\mathrm{C}$ and NPC treated with two-dimensional conformal radiotherapy (2D-CRT). ${ }^{27}$ However, the clinical significance of cystatin $\mathrm{C}$ in NPC treated with intensity-modulated radiotherapy (IMRT) is still unclear.

Therefore, we performed this retrospective cohort study to discover and verify the prognostic value of serum cystatin $\mathrm{C}$ level at the first time of diagnosis in NPC in the IMRT era, in order to assist clinicians to formulate more individualized treatment strategies for NPC patients and improve their life quality and clinical outcome.

\section{Patients and Methods}

\section{Patient Population}

A total of 2077 patients newly diagnosed with NPC at Sun Yat-Sen University Cancer Center between April 2009 and
September 2012 were analyzed retrospectively in this study. Patients were enrolled if (i) diagnosed as NPC by pathological biopsy; (ii) without distant metastasis; (iii) without previous anticancer treatment; (iv) without previous history of cancer; (v) with complete patient history and biochemical test results.

\section{Pretreatment Evaluation}

All patients participating in the study were assessed with routine pretreatment evaluation consisting of complete medical history, physical examination, routine blood test and biochemical analyses, nasopharyngoscopy, histopathological diagnosis, magnetic resonance imaging (MRI) of the nasopharynx and neck, chest radiography, abdominal ultrasonography, and whole body bone scan by single photon emission computed tomography (ECT) or $18^{\mathrm{F}}$ fluorodeoxyglucose positron-emission tomography/computed tomography (PET/CT). All patients were restaged according to the eighth edition of the American Joint Committee on Cancer (AJCC) staging system. Two radiation oncologists specializing in head and neck cancer independently reviewed all imaging scans and divergence was resolved by consultation. This study was approved by the Institutional Ethical Review Board of Sun Yat-Sen University Cancer Center, and the written informed consent was waived by the Ethics Review Board due to the anonymity of the study. This study was also conducted in accordance with the Declaration of Helsinki.

\section{Laboratory Measurements}

All patients participating in this study had serum cystatin $\mathrm{C}$ levels measured in our hospital before having any antitumor treatment. Five milliliters of peripheral blood from each patient was separated by centrifugation at $3000 \mathrm{~g}$ for five minutes and the upper serum was carefully transferred to Eppendorf Pipes. Serum cystatin C level was determined using an automated analyzer (7600-020, Hitachi High-Technologies, Tokyo, Japan), and the coefficient of variance of serum cystatin $\mathrm{C}$ measurement was less than $5 \%$.

\section{Treatment}

According to our institutional guidelines, the primary tumor and cervical malignant lymph nodes were treated with intensity-modulated radiation therapy (IMRT). The prescribed doses were 66-72 Gy (28-33 fractions) to the planning target volume (PTV) of the gross tumor volume of nasopharynx lesion (GTVnx), and 64-70 Gy (28-33 
fractions) to the PTV of the gross tumor volume of the malignant lymph nodes (GTVnd). In principal, radiation therapy alone was used for stage I disease, concurrent chemoradiotherapy for stage II disease, and concurrent chemoradiotherapy (CCRT) with or without induction/ adjuvant chemotherapy (IC/AC) for stage III-IVB disease. Three regimes of IC were commonly adopted: cisplatin $\left(80 \mathrm{mg} / \mathrm{m}^{2}\right)$ plus 5 -fluorouracil $\left(750-1000 \mathrm{mg} / \mathrm{m}^{2}\right.$ per day for five days), cisplatin $\left(75 \mathrm{mg} / \mathrm{m}^{2}\right)$ plus docetaxel $\left(75 \mathrm{mg} / \mathrm{m}^{2}\right)$, and cisplatin $\left(60 \mathrm{mg} / \mathrm{m}^{2}\right)$ plus docetaxel $\left(60 \mathrm{mg} / \mathrm{m}^{2}\right)$ and 5 -fluorouracil $\left(600-750 \mathrm{mg} / \mathrm{m}^{2}\right.$ per day for five days) every three weeks for 2-4 cycles. CCRT adopted cisplatin $\left(80-100 \mathrm{mg} / \mathrm{m}^{2}\right)$ every three weeks for $2-3$ cycles or cisplatin $\left(30-40 \mathrm{mg} / \mathrm{m}^{2}\right)$ weekly for five-toseven cycles. AC was less often chosen because of its poor compliance. Reasons for deviation from guidelines included recruitment in clinical trials, patient's refusal, age, or organ dysfunction suggesting intolerance to treatment.

\section{Follow-up}

The process of the follow-up continued from the first day of antitumor treatment to the time of last visit or death. The median follow-up time was 96.3 months (range: 4.1-120.0 months). In our study, overall survival (OS) and disease-free survival (DFS) were two clinical indicators for outcome measure. OS was defined as from the first day of antitumor treatment to death, whatever the cause; DFS was to disease progression or death whatever the cause. After a whole therapy mentioned before, we reexamined patients every three months in the first two years, every six months in the subsequent three years, and once a year henceforth until the end.

\section{Statistical Analysis}

SPSS version 22.0 (IBM Corporation, Armonk, NY, USA) was used for all statistical analysis. Chi-squared or Fisher's exact test was used to analyze the differences between categorical variables. Kaplan-Meier curve was applied to the calculation of the cumulative survival rates, and log rank test was used to compare their differences. Univariate and multivariate analysis with Cox proportional hazards models were used to look for independent predictors of prognosis of NPC patients by backward elimination of confounding variables. Host factors included age, gender, WHO type, and TNM stage were used as covariates. All tests were two-side and a $P$-value $<0.05$ was considered statistically significant.

\section{Results}

\section{Patient Characteristics}

The baseline characteristics of 2077 NPC patients are shown in Table 1. The median age of patients with NPC was 45 years (range from 18 to 78 years). Among them, $527(25.4 \%)$ patients were female and 1550 (74.6\%) were male. According to the eighth AJCC/UICC staging system, the quantity of patients classified as stage I, II, III, and IV were 120 (5.8\%), 414 (19.9\%), 968 (46.6\%), and $575(27.7 \%)$, respectively. All of those patients went radical IMRT, and 1763 patients $(84.9 \%)$ received

Table I Baseline Characteristics of 2077 Patients with Nasopharyngeal Carcinoma

\begin{tabular}{|c|c|}
\hline Characteristics & No. of Patientsn (\%) \\
\hline \multicolumn{2}{|l|}{ Age, years } \\
\hline Median & 45 \\
\hline Range & $18-78$ \\
\hline \multicolumn{2}{|l|}{ Gender } \\
\hline Female & $527(25.4)$ \\
\hline Male & I550 (74.6) \\
\hline \multicolumn{2}{|l|}{ WHO type } \\
\hline 1 & II $(0.5)$ \\
\hline II & $98(4.7)$ \\
\hline III & $1968(94.8)$ \\
\hline \multicolumn{2}{|l|}{$\mathbf{T}$ category ${ }^{\mathbf{a}}$} \\
\hline $\mathrm{TI}$ & $349(16.8)$ \\
\hline T2 & $344(16.6)$ \\
\hline T3 & $984(47.4)$ \\
\hline $\mathrm{T} 4$ & $400(19.3)$ \\
\hline \multicolumn{2}{|l|}{$\mathbf{N}$ category $^{\mathbf{a}}$} \\
\hline No & $352(16.9)$ \\
\hline $\mathrm{NI}$ & II 78 (56.7) \\
\hline N2 & $334(16.1)$ \\
\hline N3 & $213(10.3)$ \\
\hline \multicolumn{2}{|l|}{ TNM stage $^{a}$} \\
\hline I & $120(5.8)$ \\
\hline II & $414(19.9)$ \\
\hline III & $968(46.6)$ \\
\hline IV & $575(27.7)$ \\
\hline \multicolumn{2}{|l|}{ Chemotherapy } \\
\hline No & $314(15.1)$ \\
\hline Yes & 1763 (84.9) \\
\hline \multicolumn{2}{|l|}{ Comorbidity } \\
\hline No & $1377(66.3)$ \\
\hline Yes & $700(33.7)$ \\
\hline
\end{tabular}

Note: ${ }^{a}$ According to the eighth AJCC/UICC staging system. 
platinum-based chemotherapy, while 314 patients (15.1\%) did not. Median follow-up was 96.3 months (range from 4.1 to 120.0 months).

\section{Correlation of Higher Serum Cystatin C Level with Patient Characteristics}

We defined patients who had serum cystatin C level above the upper limit of the normal range $(0.59-1.03 \mathrm{mg} / \mathrm{L})$ as being in the high cystatin $\mathrm{C}$ group $(>1.03 \mathrm{mg} / \mathrm{L})$, and the remaining patients as being in the low cystatin $\mathrm{C}$ group $(\leq 1.03 \mathrm{mg} / \mathrm{L})$. Then the baseline characteristics of the two groups were compared and the results were displayed in Table 2. For the whole cohort, $362 / 2077$ (17.4\%) patients were diagnosed as high serum cystatin $\mathrm{C}(>1.03 \mathrm{mg} / \mathrm{L})$. Compared with those with low serum cystatin $\mathrm{C}$ level $(\leq 1.03 \mathrm{mg} / \mathrm{L})$, the NPC patients with high serum cystatin $\mathrm{C}$ level were older $(P<0.001)$, and they were with higher $\mathrm{T}$ category $(P<0.001)$, $\mathrm{N}$ category $(P=0.037)$, TNM stage $(P=0.004)$. Moreover, they tended to be more male $(P<0.001)$ and complicated with more comorbidities $(P<0.001)$ than those with low serum cystatin C. Additionally, there were no obvious statistical differences in terms of WHO type $(P=0.194)$ and chemotherapy $(P=0.116)$.

\section{Prognostic Value of Serum Cystatin $C$ Level in NPC}

We first analyzed the relationship of serum cystatin $\mathrm{C}$ level with the survival probabilities of NPC patients by KaplanMeier analysis. As shown in Figure 1, the NPC patients with a high level of serum cystatin $\mathrm{C}$ level had worse OS $(P<0.001)$, and DFS $(P<0.001)$ compared with those with a low level of serum cystatin $C$.

We then used univariate and multivariate Cox proportional hazards models to assess whether serum cystatin C level can predict clinical outcome of NPC patients. Univariate analysis results showed that together with age, gender, WHO type and TNM stage, serum cystatin C level can predict the clinical outcome of NPC patients, specifically high serum cystatin $\mathrm{C}$ level was associated with worse OS (HR: $1.81,95 \%$ CI: $1.46-2.24, P<0.001$, Table 3), and DFS (HR: $1.54,95 \%$ CI: $1.27-1.87, P<0.001$, Table 3 ).

Multivariate analysis further indicated that serum cystatin $\mathrm{C}$ level can be an independent predictor of OS (HR: $1.56,95 \% \mathrm{CI}: 1.25-1.95, P<0.001$, Table 4 ) and DFS (HR: $1.38,95 \% \mathrm{CI}: 1.13-1.68, P=0.002$, Table 4 ) for NPC patients. Similarly, age, WHO type and TNM stage were
Table 2 Baseline Characteristics of Nasopharyngeal Carcinoma Patients with Low or High Serum Cystatin C Levels

\begin{tabular}{|c|c|c|c|}
\hline \multirow[t]{2}{*}{ Characteristics } & \multicolumn{2}{|c|}{ Serum Cystatin C level } & \multirow[t]{2}{*}{$P$-value* } \\
\hline & $\begin{array}{l}\leq 1.03 \mathrm{mg} / \mathrm{L} \text {, } \\
\mathrm{n}(\%)\end{array}$ & $\begin{array}{l}>1.03 \mathrm{mg} / \mathrm{L}, \\
\mathrm{n}(\%)\end{array}$ & \\
\hline \multicolumn{4}{|l|}{ Age } \\
\hline$\leq 45$ years & 1007 (58.7) & $103(28.5)$ & $<0.001 * *$ \\
\hline$>45$ years & $708(41.3)$ & 259 (7I.5) & \\
\hline \multicolumn{4}{|l|}{ Gender } \\
\hline Female & $482(28.1)$ & $45(12.4)$ & $<0.001 * *$ \\
\hline Male & 1233 (7I.9) & $317(87.6)$ & \\
\hline \multicolumn{4}{|l|}{ WHO type } \\
\hline$I+I I$ & $85(5.0)$ & $24(6.6)$ & 0.194 \\
\hline III & $1630(95.0)$ & $338(93.4)$ & \\
\hline \multicolumn{4}{|l|}{$\mathbf{T}$ category ${ }^{\mathbf{a}}$} \\
\hline TI & $312(18.2)$ & $37(10.2)$ & $<0.001 * *$ \\
\hline T2 & $266(15.5)$ & $78(21.5)$ & \\
\hline T3 & $821(47.9)$ & $163(45.0)$ & \\
\hline T4 & $316(18.4)$ & $84(23.2)$ & \\
\hline \multicolumn{4}{|l|}{$\mathbf{N}$ category $^{a}$} \\
\hline No & $299(17.4)$ & $53(14.6)$ & $0.037^{* *}$ \\
\hline $\mathrm{NI}$ & $985(57.4)$ & $193(53.3)$ & \\
\hline N2 & $267(15.6)$ & $67(18.5)$ & \\
\hline N3 & $164(9.6)$ & $49(13.5)$ & \\
\hline \multicolumn{4}{|l|}{ TNM stage $\mathrm{e}^{\mathrm{a}}$} \\
\hline 1 & $109(6.4)$ & II (3.0) & $0.004 * *$ \\
\hline II & $345(20.1)$ & $69(19.1)$ & \\
\hline III & $810(47.2)$ & $158(43.6)$ & \\
\hline IV & $451(26.3)$ & $124(34.3)$ & \\
\hline \multicolumn{4}{|l|}{ Chemotherapy } \\
\hline No & $269(15.7)$ & $45(12.4)$ & 0.116 \\
\hline Yes & I 446 (84.3) & $317(87.6)$ & \\
\hline \multicolumn{4}{|l|}{ Comorbidity } \\
\hline No & $1169(68.2)$ & $208(57.5)$ & $<0.001 * *$ \\
\hline Yes & $546(31.8)$ & 154 (42.5) & \\
\hline
\end{tabular}

Notes: $* P$-value was calculated using the chi-squared tests or Fisher's exact test. $* * P<0.05 .{ }^{a}$ According to the eighth AJCC/UICC staging system.

independent predictors of OS and DFS for NPC patients (all $P<0.05$, Table 4).

\section{Varying Impact of Serum Cystatin C Level by Stage}

As shown in Table 2, two groups of NPC patients had different TNM stage distribution $(P=0.004)$. Then, we performed a subgroup analysis based on clinical TNM stage by dividing the patients into two groups (I-II: earlystage group and III-IV: advanced-stage group). Survival 

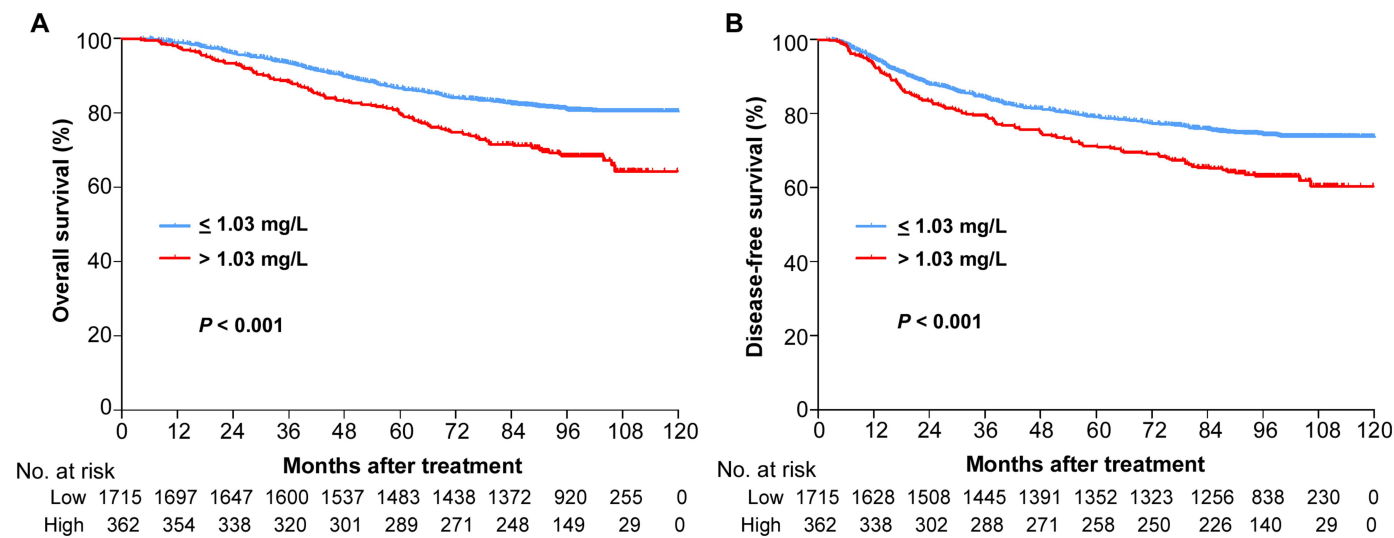

Figure I Kaplan-Meier curve analysis of survival probabilities of NPC patients stratified by the level of serum cystatin C. (A) Overall survival, (B) Disease-free survival.

analysis results showed that compared with patients with low serum cystatin $\mathrm{C}$ level, early-stage patients with high serum cystatin $\mathrm{C}$ level had poorer OS $(P=0.018$, Figure $2 \mathrm{~A})$, but had no significant statistical difference in DFS $(P=0.252$, Figure $2 \mathrm{~B})$, and advanced-stage patients with high serum cystatin $\mathrm{C}$ level had both poorer OS $(P<0.001$, Figure $2 \mathrm{C})$ and DFS $(P<0.001$, Figure 2D).

\section{Discussion}

To the best of our knowledge, this study is the largest retrospective cohort study to assess the relationship between serum cystatin $\mathrm{C}$ level and the prognosis of

Table 3 Univariate Analysis of Prognostic Factors in Patients with Nasopharyngeal Carcinoma

\begin{tabular}{|c|c|c|c|}
\hline \multirow[t]{2}{*}{ Variables } & \multicolumn{3}{|c|}{ Univariate Analysis } \\
\hline & HR & $95 \% \mathrm{Cl}$ & $P$-value* \\
\hline \multicolumn{4}{|l|}{ Overall survival } \\
\hline Age ( $>45$ years vs $\leq 45$ years) & 1.58 & $1.31-1.90$ & $<0.001 * *$ \\
\hline Gender (female vs male) & 0.75 & $0.60-0.94$ & $0.014^{* *}$ \\
\hline WHO type (III vs I+II) & 0.58 & $0.4 I-0.8 I$ & $0.002^{* *}$ \\
\hline TNM stage (III-IV vs I-II) & 3.01 & $2.24-4.04$ & $<0.001 * *$ \\
\hline Comorbidity (with vs without) & 1.13 & $0.93-1.37$ & 0.228 \\
\hline $\begin{array}{l}\text { Serum cystatin } C \text { level (high vs } \\
\text { low) }\end{array}$ & 1.81 & $1.46-2.24$ & $<0.001 * *$ \\
\hline \multicolumn{4}{|l|}{ Disease-free survival } \\
\hline Age ( $>45$ years vs $\leq 45$ years) & $1.4 \mathrm{I}$ & $1.20-1.66$ & $<0.001 * *$ \\
\hline Gender (female vs male) & 0.80 & $0.66-0.97$ & $0.026 * *$ \\
\hline WHO type (III vs I+II) & 0.64 & $0.46-0.87$ & $0.005^{* *}$ \\
\hline TNM stage (III-IV vs I-II) & 2.26 & I.79-2.85 & $<0.001 * *$ \\
\hline Comorbidity (with vs without) & 1.06 & $0.89-1.26$ & 0.505 \\
\hline $\begin{array}{l}\text { Serum cystatin } C \text { level (high vs } \\
\text { low) }\end{array}$ & 1.54 & $1.27-1.87$ & $<0.001 * *$ \\
\hline
\end{tabular}

Notes: $* P$-value was calculated using the univariate Cox proportional hazards model. $* * P<0.05$
NPC patients treated with IMRT. Our results revealed that high serum cystatin $\mathrm{C}$ level can independently predict poor clinical outcome of patients with NPC. Therefore, monitoring serum cystatin $\mathrm{C}$ level before antitumor treatment can assist clinicians to formulate more individualized treatment strategies for NPC patients and improve their life quality and survival.

The standard treatment for NPC is mainly effective in local symptomatic control, but not in distant metastasis. $^{28,29}$ Therefore, it remains an urgent problem to predict the prognosis and prolong the survival of NPC patients at different stages. At present, TNM staging system is the most commonly used tool to determine the

Table 4 Multivariable Analysis of Prognostic Factors in Patients with Nasopharyngeal Carcinoma

\begin{tabular}{|l|l|l|l|}
\hline \multirow{2}{*}{ Variables } & \multicolumn{3}{|l|}{ Multivariate Analysis } \\
\cline { 2 - 4 } & HR & $\mathbf{9 5 \% C I}$ & P-value* \\
\hline Overall survival & & & \\
Age (>45 years vs $\leq 45$ years) & $I .40$ & $I . I 5-I .70$ & $0.00 I^{* *}$ \\
WHO type (III vs I+II) & 0.58 & $0.42-0.82$ & $0.002^{* *}$ \\
TNM stage (III-IV vs I-II) & 2.96 & $2.2 I-3.98$ & $<0.00 I^{* *}$ \\
Serum cystatin C level (high vs & $I .56$ & $I .25-I .95$ & $<0.00 I^{* *}$ \\
low) & & & \\
\hline Disease-free survival & & & \\
Age (>45 years vs $\leq 45$ years) & $I .29$ & $I .09-I .53$ & $0.003^{* *}$ \\
WHO type (III vs I+II) & 0.64 & $0.47-0.87$ & $0.005^{* *}$ \\
TNM stage (III-IV vs I-II) & 2.24 & $I .78-2.82$ & $<0.00 I^{* *}$ \\
Serum cystatin C level (High vs & $I .38$ & $I .13-I .68$ & $0.002^{* *}$ \\
Low) & & & \\
\hline
\end{tabular}

Notes: *-value was calculated using the multivariable Cox proportional hazards model. **P<0.05. The following parameters were included in the Cox proportion hazard model by backward elimination: age ( $\geq 45$ vs $<45$ years), gender (female vs male), WHO type (type III vs type I+II), TNM stage (III-IV vs I-II), comorbidity (with vs without), and serum cystatin $C$ level (high vs low) as covariates. 

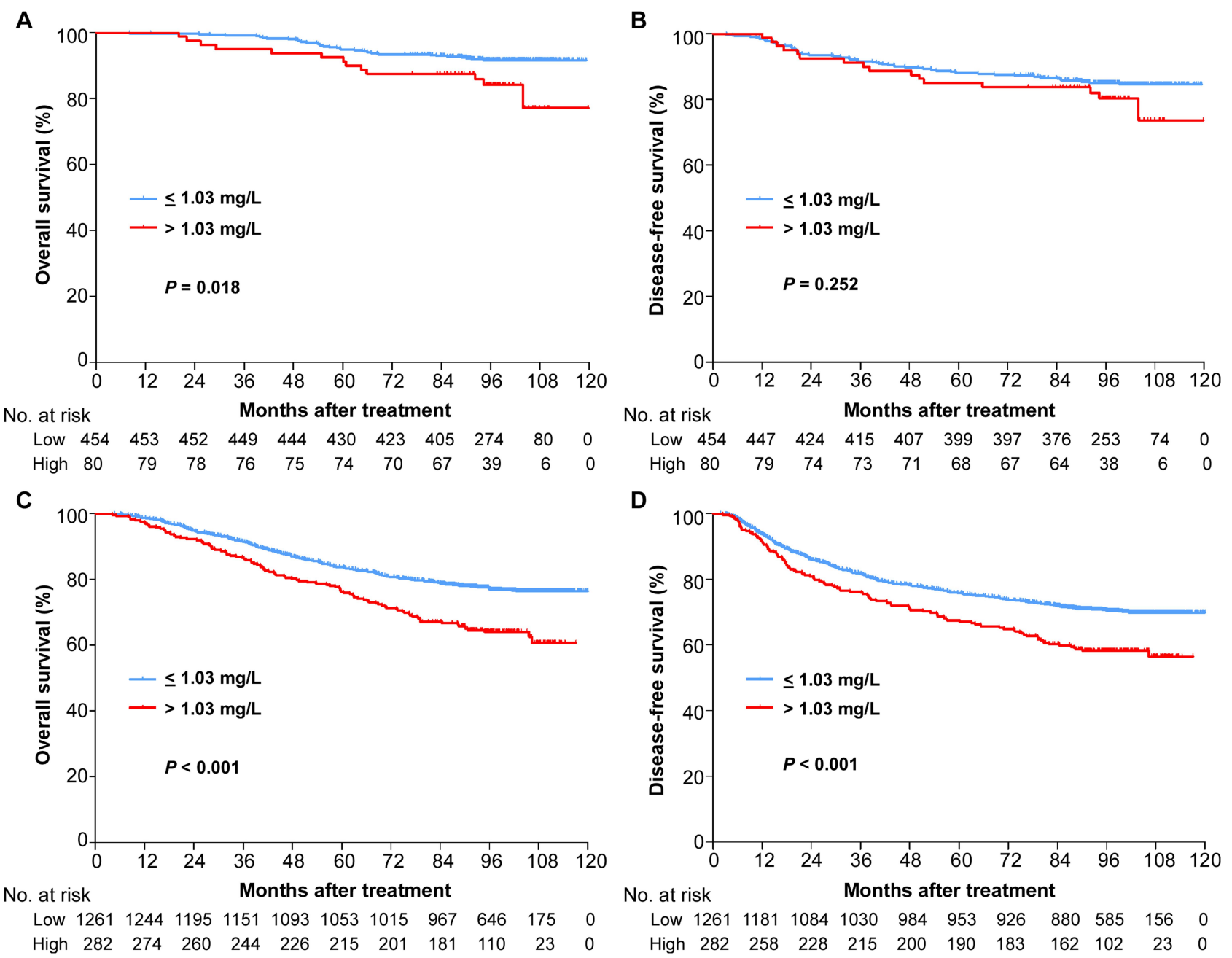

Figure 2 Kaplan-Meier curve analysis of survival probabilities of NPC patients stratified by TNM stage and the level of serum cystatin C. (A) Overall survival in early-stage, (B) Disease-free survival in early-stage, (C) Overall survival in advanced-stage, (D) Disease-free survival in advanced-stage.

prognosis of patients with NPC. However, studies have shown that patients with the same TNM stage have a different prognosis after receiving the same treatment regimen. ${ }^{8}$ This shows that TNM staging has limitations in predicting the survival of patients with NPC, and new biomarkers are needed to increase the accuracy of TNM staging in predicting the prognosis of patients with NPC. Serum cystatin $\mathrm{C}$ is a cysteine protease inhibitor and has been reported to be a significant predictor to carry prognostic or diagnostic information in human diseases, including various malignant cancers. ${ }^{17-26}$ However, a study regarding the predictive value of serum cystatin $\mathrm{C}$ on NPC patients treated with IMRT has not been reported yet.

Here, we conducted this retrospective study, with 2077 patients and a median follow-up time of 96.3 months (range from 4.1 to 120.0 months), to evaluate the impact of serum cystatin C on NPC patients treated with IMRT.
Our results demonstrated that patients with high serum cystatin $\mathrm{C}$ level before antitumor treatment tend to get shorter OS, as well as shorter DFS. Furthermore, in multivariable analysis, we found that the pretreatment level of serum cystatin $\mathrm{C}$ level is a significant predictor of inferior prognosis in NPC patients. And the subgroup analysis based on TNM stage revealed that advanced patients with high serum cystatin $\mathrm{C}$ level had shorter OS and DFS, which was in accordance with the results inthe whole cohort of our patients.

The molecular role of serum cystatin $\mathrm{C}$ level in clinical outcome of NPC remains unknown. Cystatin C genes, sharing some common features with housekeeping genes, are expressed among most human tissues, such as lung, liver, kidney, stomach, pancreas. ${ }^{30}$ Most of the cystatin C exist in cerebrospinal fluid, semen, and also in milk, synovial fluid, saliva, tears, serum, and urine. ${ }^{31}$ Researchers 
believe that the level of cystatin is associated with age. $^{32-34}$ Filler et al found that cystatin $\mathrm{C}$ is stable among 1 50-year-old people, while its level gets higher in the elderly due to renal impairment. ${ }^{32}$ Odden et al reported that older people had a higher level of cystatin than younger people. ${ }^{33}$ Stephen et al came to the same conclusion, and suggested that the burden of disease, depressive symptoms, physical inactivity, and BMI were partly to blame. ${ }^{34}$ Due to its inhibiting activity on lysosomal cysteine proteinases, some in vitro and in vivo studies have reported that cystatin $\mathrm{C}$ acts as a tumor suppressor in some cancers to take control of key steps of cell proliferation, invasion, angiogenesis and metastasis in tumor biological process. ${ }^{35-37}$ But different opinions showed that cystatin $\mathrm{C}$ can drive the biological process of a plenty of malignancies, such as ovarian cancer, ${ }^{36}$ prostate cancer, ${ }^{38}$ and so on. The precise molecular role of cystatin C in NPC biological process are still unclear.

In terms of molecular mechanism underlying cystatin $\mathrm{C}$ in cancers, Wegiel et al found that serum cystatin $\mathrm{C}$ inhibited tumor invasion via MAPK/ERK pathway and had a crosstalk with androgen receptor mediated pathways. ${ }^{39}$ Yan et al identified that long noncoding RNASNHG1 directly bound microRNA-338 to upregulate the expression of CST3 (Cystatin C), leading to promote cancer cell growth. ${ }^{40}$ Mori et al found that activated p53 upregulated cystatin $\mathrm{C}$ expression through p53 binding sequence in the first intron to increase adriamycininduced apoptosis. ${ }^{41}$ Only one study showed that the level of cystatin $\mathrm{C}$, secreted by epidermal growth factor receptor, was decreased under TGF- $\alpha$ stimulation in NPC cell. $^{42}$ A recent study appealed uncontrolled cystatin $\mathrm{C}$ may result in tumor progression, as a consequence of unbalanced immune system. ${ }^{43}$ The molecular mechanism underlying the relationship of cystatin $\mathrm{C}$ and prognosis of NPC patients and whether cystatin $\mathrm{C}$ can become a therapeutic target need to be further explored in in vivo and in vitro experiments.

Some limitations in our design should be stated, although our study has clear strengths including the larger database and complete clinical data of patients. Firstly, our study is based on a monocenter, indeed results of this study should be validated by more research institutions. Secondly, the existed selection bias and potential confounding factors in our retrospective study could not be eliminated completely. Thirdly, as stated before, the potential mechanisms should be further investigated.

\section{Conclusion}

In conclusion, this is the largest retrospective cohort study with 2077 NPC patients treated with IMRT. We found that high serum cystatin $\mathrm{C}$ level was associated with worse prognosis of NPC patients, particularly advanced patients. Serum cystatin $\mathrm{C}$ was a significant and independent prognostic predictor of NPC and could guide more effective and accurate clinical therapeutic strategy decision. More future studies are needed to explore the molecular regulatory mechanisms underlying serum cystatin $\mathrm{C}$ level and prognosis of NPC patients.

\section{Abbreviations}

NPC, nasopharyngeal carcinoma; AJCC, American Joint Committee on Cancer; UICC, International Union against Cancer; OS, overall survival; DFS, disease-free survival; MRI, magnetic resonance imaging; ECT, emission computed tomography; PET/CT, 18F-fluorodeoxyglucose positron-emission tomography/computed tomography; PTV, planning target volume; GTVnx, gross tumor volume of nasopharynx lesion; GTVnd, gross tumor volume of the malignant lymph nodes.

\section{Data Sharing Statement}

The data that support the findings of this study are available from the corresponding author upon reasonable request. The key raw data have been uploaded onto the Research Data Deposit public platform (http://www. researchdata.org.cn), with the approval number RDDA2021001828. The authors report no conflicts of interest in this work.

\section{Acknowledgments}

This work was supported by grants from the Natural Science Foundation of Guangdong Province (No. 2018B030306045), and the Guangdong Special Support Program (No. 2017TQ04R754).

\section{Funding}

This work was supported by grants from the Natural Science Foundation of Guangdong Province (No. 2018B030306045), and the Guangdong Special Support Program (No. 2017TQ04R754).

\section{Disclosure}

The authors report no conflicts of interest in this work. 


\section{References}

1. Torre LA, Bray F, Siegel RL, et al. Global cancer statistics, 2012. $C A$ Cancer J Clin. 2015;65(2):87-108.

2. Tham IW, Lu JJ. Controversies and challenges in the current management of nasopharyngeal cancer. Expert Rev Anticancer Ther. 2010;10 (9):1439-1450. doi:10.1586/era.10.97

3. Lee AWM, Lin JC, Ng WT. Current management of nasopharyngeal cancer. Semin Radiat Oncol. 2012;22(3):233-234. doi:10.1016/j. semradonc.2012.03.008

4. Bray F, Ferlay J, Soerjomataram I, et al. Global cancer statistics 2018: GLOBOCAN estimates of incidence and mortality worldwide for 36 cancers in 185 countries. Chin J Cancer. 2018;68(6):394-424.

5. Lai SZ, Li WF, Chen L, et al. How does intensity-modulated radiotherapy versus conventional two-dimensional radiotherapy influence the treatment results in nasopharyngeal carcinoma patients? Int J Radiat Oncol Biol Phys. 2011;80(3):661-668. doi:10.1016/j. ijrobp.2010.03.024

6. Liu N, Chen NY, Cui RX, et al. Prognostic value of a microRNA signature in nasopharyngeal carcinoma: a microRNA expression analysis. Lancet Oncol. 2012;13(6):633-641. doi:10.1016/S14702045(12)70102-X

7. Takes RP, Rinaldo A, Silver CE, et al. Future of the TNM classification and staging system in head and neck cancer. Head Neck. 2010;32 (12):1693-1711. doi:10.1002/hed.21361

8. Lee AWM, Ng WT, Chan LK, et al. The strength/weakness of the AJCC/UICC staging system (7th edition) for nasopharyngeal cancer and suggestions for future improvement. Oral Oncol. 2012;48 (10):1007-1013. doi:10.1016/j.oraloncology.2012.03.022

9. Du XJ, Tang LL, Mao YP, et al. The pretreatment albumin to globulin ratio has predictive value for long-term mortality in nasopharyngeal carcinoma. PLoS One. 2014;9(4):e94473. doi:10.1371/journal. pone. 0094473

10. Zhou GQ, Ren XY, Mao YP, et al. Prognostic implications of dynamic serum lactate dehydrogenase assessments in nasopharyngeal carcinoma patients treated with intensity-modulated radiotherapy. Sci Rep. 2016;6(1):22326. doi:10.1038/srep22326

11. Zhang Y, Zhou GQ, Liu X, et al. Exploration and validation of C-reactive protein/albumin ratio as a novel inflammation-based prognostic marker in nasopharyngeal carcinoma. J Cancer. 2016;7 (11):1406-1412. doi:10.7150/jca.15401

12. Yao JJ, Kou J, Peng QH, et al. Prognostic value of serum bilirubin in southern Chinese patients with advanced nasopharyngeal carcinoma. Clin Chim Acta. 2018;484:314-319. doi:10.1016/j.cca.2018.05.058

13. Yao JJ, He XJ, Lawrence WR, et al. Prognostic value of circulating lipoprotein in patients with locoregionally advanced nasopharyngeal carcinoma. Cell Physio Biochem. 2018;48(1):285-292. doi:10.1159/ 000491728

14. Lam WKJ, Chan KCA, Lo YMD. Plasma Epstein-Barr virus DNA as an archetypal circulating tumour DNA marker. J Pathol. 2019;247 (5):641-649. doi:10.1002/path.5249

15. Pogorzelska A, Żołnowska B, Bartoszewski R. Cysteine cathepsins as a prospective target for anticancer therapies-current progress and prospects. Biochimie. 2018;151:85-106. doi:10.1016/j.biochi.2018. 05.023

16. Sokol JP, Schiemann WP. Cystatin C antagonizes transforming growth factor beta signaling in normal and cancer cells. Mol Cancer Res. 2004;2(3):183-195.

17. Adachi M, Tanaka A, Aiso M, et al. Benefit of cystatin C in evaluation of renal function and prediction of survival in patients with cirrhosis. Hepatol Res. 2015;45(13):1299-1306. doi:10.1111/ hepr. 12508

18. Dedual MA, Wueest S, Challa TD, et al. Obesity-induced increase in cystatin C alleviates tissue inflammation. Diabetes. 2020;69 (9):1927-1935. doi:10.2337/db19-1206
19. Dong XY, Zheng DM, Nao JF. Measurement of serum cystatin C: a valuable tool for evaluating dyskinesia in Parkinson's disease. Neurosci Lett. 2019;705:172-176. doi:10.1016/j.neulet.2019.05.002

20. Ogawa-Akiyama A, Sugiyama H, Kitagawa M, et al. Serum cystatin $\mathrm{C}$ is an independent biomarker associated with the renal resistive index in patients with chronic kidney disease. PLoS One. 2018;13(3): e0193695. doi:10.1371/journal.pone.0193695

21. Einwoegerer CF, Domingueti CP. Association between increased levels of cystatin $\mathrm{c}$ and the development of cardiovascular events or mortality: a systematic review and meta-analysis. Arq Bras Cardiol. 2018;111(6):796-807.

22. Terpos E, Katodritou E, Tsiftsakis E, et al. Cystatin-C is an independent prognostic factor for survival in multiple myeloma and is reduced by bortezomib administration. Haematologica. 2009;94 (3):372-379. doi:10.3324/haematol.2008.000638

23. Yan Y, Zhou K, Wang LP, et al. Clinical significance of serum cathepsin $\mathrm{B}$ and cystatin $\mathrm{C}$ levels and their ratio in the prognosis of patients with esophageal cancer. OncoTargets Ther. 2017; Volume 10 (10):1947-1954. doi:10.2147/OTT.S123042

24. Guo KB, Chen QH, He XB, et al. Expression and significance of cystatin-C in clear cell renal cell carcinoma. Biomed Pharmacother. 2018;107:1237-1245. doi:10.1016/j.biopha.2018.08.083

25. Tan P, Shi M, Chen J, et al. The preoperative serum cystatin-C as an independent prognostic factor for survival in upper tract urothelial carcinoma. Asian J Androl. 2019;21(2):163-169. doi:10.4103/aja. aja_84_18

26. Mulaomerović A, Halilbasić A, Cickusić E, et al. Cystatin C as a potential marker for relapse in patients with non-Hodgkin B-cell lymphoma. Cancer Lett. 2007;248(2):192-197. doi:10.1016/j. canlet.2006.07.004

27. Yuan J, Xu M, Li J, et al. Prognostic value of cystatin C in patients with nasopharyngeal carcinoma: a retrospective study of 1063 patients. Clinics. 2016;71(6):338-343. doi:10.6061/clinics/2016(06)09

28. Chen MY, Jiang R, Guo L, et al. Locoregional radiotherapy in patients with distant metastases of nasopharyngeal carcinoma at diagnosis. Chin J Cancer. 2013;32(11):604-613. doi:10.5732/cjc.013.10148

29. Hui EP, Leung SF, Au JSK, et al. Lung metastasis alone in nasopharyngeal carcinoma: a relatively favorable prognostic group. Cancer. 2004;01(2):300-306. doi:10.1002/cncr.20358

30. Abrahamson M, Olafsso I, Palsdottir A, et al. Structure and expression of the human cystatin C gene. Biochem J. 1990;268(2):287-294. doi:10.1042/bj2680287

31. Mussap M, Plebani M. Biochemistry and clinical role of human cystatin C. Crit Rev Clin Lab Sci. 2004;41(5-6):467-550.

32. Filler G, Bökenkamp A, Hofmann W, et al. Cystatin C as a marker of GFR-history, indications, and future research. Clin Biochem. 2005;38 (1):1-8. doi:10.1016/j.clinbiochem.2004.09.025

33. Odden MC, Tager IB, Gansevoort RT, et al. Age and cystatin C in healthy adults: a collaborative study. Nephrol Dial Transplant. 2010;25(2):463-469. doi:10.1093/ndt/gfp474

34. Stephan Y, Sutin AR, Terracciano A. Subjective age and cystatin C among older adults. J Gerontol B Psychol Sci Soc Sci. 2019;74 (3):382-388. doi:10.1093/geronb/gbx124

35. Hu YL, Hung AC, Cui H, et al. Role of cystatin $\mathrm{C}$ in amyloid precursor protein-induced proliferation of neural stem/progenitor cells. $J$ Bio Chem. 2013;288(26):18853-18862. doi:10.1074/jbc.M112.443671

36. Nishikawa H, Ozaki Y, Nakanishi T, et al. The role of cathepsin B and cystatin $\mathrm{C}$ in the mechanisms of invasion by ovarian cancer. Gynecol Oncol. 2004;92(3):881-886. doi:10.1016/j.ygyno.2003.11.017

37. Olson OC, Joyce JA. Cysteine cathepsin proteases: regulators of cancer progression and therapeutic response. Nat Rev Cancer. 2015;15(12):712-729. doi:10.1038/nrc4027

38. Jiborn T, Abrahamson M, Gadaleanu V, et al. Aberrant expression of cystatin $\mathrm{C}$ in prostate cancer is associated with neuroendocrine differentiation. BJU Int. 2006;98(1):189-196. doi:10.1111/j.1464410X.2006.06345.x 
39. Wegiel B, Jiborn T, Abrahamson M, et al. Cystatin C is downregulated in prostate cancer and modulates invasion of prostate cancer cells via MAPK/Erk and androgen receptor pathways. PLoS One. 2009;4(11):e7953. doi:10.1371/journal.pone.0007953

40. Yan Y, Fan QX, Wang LP, et al. LncRNA Snhg1, a non-degradable sponge for miR-338, promotes expression of proto-oncogene CST3 in primary esophageal cancer cells. Oncotarget. 2017;8(22):35 750-35760.

41. Mori J, Tanikawa C, Funauchi Y, et al. Cystatin C as a p53-inducible apoptotic mediator that regulates cathepsin L activity. Cancer Sci. 2016;107(3):298-306. doi:10.1111/cas.12881
42. Tang CE, Guan YJ, Yi B, et al. Identification of the amyloid $\beta$-protein precursor and cystatin $\mathrm{C}$ as novel epidermal growth factor receptor regulated secretory proteins in nasopharyngeal carcinoma by proteomics. J Proteome Res. 2010;9(12):6101-6111.

43. $\mathrm{Zi} \mathrm{MT,} \mathrm{Xu} \mathrm{YK.} \mathrm{Involvement} \mathrm{of} \mathrm{cystatin} \mathrm{C}$ in immunity and apoptosis. Immunol Lett. 2018;196:80-90. doi:10.1016/j.imlet.2018. 01.006

\section{Publish your work in this journal}

OncoTargets and Therapy is an international, peer-reviewed, open access journal focusing on the pathological basis of all cancers, potential targets for therapy and treatment protocols employed to improve the management of cancer patients. The journal also focuses on the impact of management programs and new therapeutic

Submit your manuscript here: https://www.dovepress.com/oncotargets-and-therapy-journa agents and protocols on patient perspectives such as quality of life, adherence and satisfaction. The manuscript management system is completely online and includes a very quick and fair peer-review system, which is all easy to use. Visit http://www.dovepress.com/ testimonials.php to read real quotes from published authors. 